\title{
openheart Understanding haemorrhagic risk following thrombolytic therapy in patients with intermediate-risk and high-risk pulmonary embolism: a hypothesis paper
}

\author{
Paul Abraham, , ${ }^{1,2}$ Diego A Arroyo, ${ }^{1,2,3}$ Raphael Giraud, ${ }^{1,2}$ Henri Bounameaux, ${ }^{4}$ \\ Karim Bendjelid ${ }^{1,2}$
}

To cite: Abraham P, Arroyo DA, Giraud R, et al. Understanding haemorrhagic risk following thrombolytic therapy in patients with intermediate-risk and highrisk pulmonary embolism: a hypothesis paper. Open Heart 2018;5:e000735. doi:10.1136/ openhrt-2017-000735

PA and DAA contributed equally.

Received 11 0ctober 2017 Revised 23 January 2018 Accepted 30 January 2018
Check for updates

${ }^{1}$ Intensive Care Unit, Geneva University Hospitals, Geneva, Switzerland

${ }^{2}$ Geneva Hemodynamic Research Group, Geneva, Switzerland

${ }^{3}$ Department of Cardiology, University and Hospital Fribourg, Fribourg, Switzerland ${ }^{4}$ Division of Angiology and Hemostasis, Geneva University Hospitals and Faculty of Medicine, Geneva, Switzerland

Correspondence to Professor Karim Bendjelid; karim.bendjelid@hcuge.ch

\section{ABSTRACT}

While systemic intravenous thrombolysis decreases mortality in patients with high-risk pulmonary embolism (PE), it clearly increases haemorrhagic risk. There are many contraindications to thrombolysis, and efforts should aim at selecting those patients who will benefit most, without suffering complications. The current review summarises the evidence for the use of thrombolytic therapy in PE. It clarifies the pathophysiological mechanisms in PE and acute cor pulmonale that increase the risk of bleeding following thrombolysis. It discusses future management challenges, namely tailored drug administration, new treatment monitoring techniques and catheter-directed thrombolysis.

\section{INTRODUCTION}

Pulmonary embolism (PE) is a leading cause of sudden death in adults. ${ }^{1}$ However, the improvement of diagnostic and treatment strategies has not led to a better survival. ${ }^{2}$ One of the keys for the management of intermediate-high-risk and high-risk PE has been intravenous thrombolysis. The history of thrombolytic therapy goes back to the early $1930 \mathrm{~s}^{3}$ when the therapy was used to dissolve hemothoraces, empyema and abscess cavities. $^{4}$ Intravenous streptokinase was first used in myocardial infarction (MI) in $1958 .{ }^{5}$ Improved survival was however demonstrated in this indication in the 1980s with the publication of the first large-scale randomised GISSI-I trial. ${ }^{6}$ Hirsch et al claimed in 1968 that streptokinase was superior to heparin in the treatment of PE. ${ }^{7}$ Thereafter, other thrombolytic agents, such as tissue plasminogen activator ( $\mathrm{t}-\mathrm{PA})$, were developed and tested in a large number of clinical trials. ${ }^{8}$ All demonstrated a benefit in critical settings such as MI and severe PE, but they also revealed an increased bleeding risk. ${ }^{8}$ This risk-benefit equilibrium has left some confusion as to the potential impact in our daily clinical practice. In this review, we present the rationale and evidence behind the use of thrombolytic therapy in PE. We also attempt to identify a subset of pathophysiological mechanisms that may influence the risk of bleeding. Finally, we address some key issues that may affect the future management of PE.

\section{INCREASED BLEEDING RISK FOLLOWING THROMBOLYSIS IN PE}

The treatment of PE has followed a similar path to that of MI both in terms of therapeutic advancements and changes in management. Thus, understanding the effects of thrombolysis in ST-segment elevation MI (STEMI), for which numerous very large randomised studies have been conducted, undoubtedly helps to understand the effects in patients with PE. ${ }^{9}$ In 1992, Levine et al reviewed the haemorrhagic complications of thrombolytic therapy in both MI and venous thromboembolism. ${ }^{10}$ First, the authors observed a higher rate of bleeding associated with thrombolytic therapy in patients with PE compared with MI. They hypothesised that this could be due to a more prolonged period of lytic therapy, as well as an increase in patient comorbidities. Second, they identified older age, smaller stature and female gender as risk factors for major extracranial bleeding in patients with MI. These were also risk factors for intracranial bleeding in PE. Additionally, aggressive adjunctive therapy with heparin increased the risk of intracranial bleeding associated with thrombolytic therapy.

Several recent meta-analyses have appraised the risk of bleeding associated with thrombolysis in PE. ${ }^{11-13}$ Unfortunately, there is only limited credit that can be given to the 
available data which is both limited in size and skewed by significant heterogeneity in patient selection and treatment regimens (table 1 ). If all-cause mortality was lower in the thrombolysis group $(2.2 \%$ vs $3.9 \%$; OR $0.53,95 \%$ CI 0.32 to 0.88 ) for patients $<65$ years, ${ }^{11}$ the mortality benefit was lost in patients $>65$ years of age or after the exclusion of high-risk patients with PE (OR $0.64,95 \%$ CI 0.35 to 1.17). ${ }^{12}$ This benefit was at the cost of an increased risk of haemorrhagic complications: $9.2 \%$ in the thrombolysis group versus $3.4 \%$ in the anticoagulation group (OR $2.73,95 \%$ CI 1.91 to 3.91$)$. As expected, the rates of intracranial haemorrhage (ICH) were higher in the thrombolysis patients ( $1.5 \%$ vs $0.2 \%$; OR $4.63,95 \%$ CI 1.78 to 12.04) with a number needed to harm of 78 patients. ${ }^{13}$ Finally, the association between thrombolytic therapy and the risk of major bleeding was lower in studies using an upper age limit (OR 1.13, 95\% CI 0.47 to 2.71) compared with studies including older patients (OR 3.71, 95\% CI 2.32 to 5.92$)(\mathrm{P}=0.02) .{ }^{12}$ Similarly, risk of fatal or $\mathrm{ICH}$ was lower in studies with an upper age limit (OR 1.82, 95\% CI 0.37 to 8.93 ) than those without (OR $4.11,95 \%$ CI 1.25 to 13.5), but not reaching statistical significance $(\mathrm{P}=0.42){ }^{12}$

There were no differences between invasive and non-invasive procedures, and alteplase showed a lower risk of bleeding compared with tenecteplase. ${ }^{12}$

Regarding older patients who did not benefit from thrombolysis in terms of mortality, important confounding factors were found: (1) the inclusion of different thrombolytic agents at varying doses; (2) poor definitions of haemodynamic stability/instability; and finally, (3) the inability to distinguish the benefits from systemic versus catheter-directed therapy. However, when the results of all randomised controlled trials (RCTs) were combined regardless of the type of PE (stable or unstable), thrombolysis still significantly reduced overall mortality compared with anticoagulation alone $(2.29 \%$ (24/1046) vs $4.03 \%$ (42/1041); OR $0.57,95 \%$ CI 0.35 to 0.92) with a number needed to treat of 57 patients. ${ }^{13}$ In addition, when all studies were combined, thrombolysis significantly decreased the risk of PE recurrence $(1.91 \%$ $(19 / 995)$ vs $4.43 \%$ (44/993); OR $0.42,95 \%$ CI 0.24 to 0.72 ). Once again, caution must be taken in interpreting pooled data from heterogeneous clinical trials.

Despite improved management of concomitant heparin infusion, a closer surveillance of haemostasis, an increased knowledge in the risk factors for bleeding and finally, a better selection of patients who may benefit from thrombolysis, the incidence of bleeding is still high in modern trials. Moreover, some registries of unselected patients have also reported higher rates of major bleeding. In 304 patients from the International Cooperative Pulmonary Embolism Registry who received fibrinolysis, $66(21.7 \%)$ had major bleeding and $9(3 \%)$ had ICH. ${ }^{14}$ Moreover, the rates of major bleeding associated with heparin infusion alone in the same registry were around $15 \% .{ }^{14}$ Additional data from a tertiary centre in Paris showed that, of 132 patients receiving thrombolysis, $33(25 \%)$ experienced major bleeding. ${ }^{15}$
To date, only one RCT tested the use of thrombolysis in PE with cardiogenic shock. ${ }^{16}$ Four patients were enrolled in each arm, and the study was prematurely terminated after a marked statistical difference in mortality in favour of thrombolysis $(0 \%$ in the thrombolysis group vs $100 \%$ in the heparin group, $\mathrm{P}=0.02)$. Thrombolysis remains the standard of care for unstable PE with shock, and further confirmatory studies are unlikely to be conducted in this indication.

With regards to STEMI, percutaneous coronary intervention (PCI) is favoured over thrombolysis because of the improved combined outcomes of death, stroke and repeat MI. Infarct area size is likely greater in thrombolysis than with PCI. For every 1000 patients treated with PCI versus thrombolysis, 23 lives are saved, while $44 \mathrm{MI}$ and 11 strokes are prevented. Moreover, patients treated with PCI have a decreased risk of intracerebral haemorrhage. ${ }^{1718}$ Despite this, thrombolysis remains the standard of care for patients with STEMI who do not have access to a PCI-capable facility within $120 \mathrm{~min}$ of first medical contact. ${ }^{9}$ Of importance, patients receiving thrombolysis for STEMI also receive anticoagulation and dual antiplatelet therapy, but the risk of intracerebral haemorrhage remains $<1 \% .{ }^{19}$ Despite this, the incidence of bleeding associated with thrombolysis in PE is much higher than in MI. ${ }^{20}$ Table 1 summarises the results of 17 randomised studies of thrombolysis in PE and the reported events of major, fatal or intracranial bleeding. ${ }^{10} 1621-35$

\section{Risk factors for bleeding after thrombolysis (in PE and STEMI)}

How do we explain the increased incidence in bleeding complications for PE? There are little data on the risk factors for bleeding after thrombolysis in PE. As mentioned above, age (with a possible threshold at 65 years) is a preponderant factor. Although not statistically significant, one randomised trial found that both age $>75$ years (OR 2.8, 95\% CI 1 to 7.86 ) and female gender (OR 11.49, 95\% CI 2.67 to 49.53 ) could be associated with higher rates of major extracranial bleeding ( $11.1 \%$ vs $8 \%$, respectively).$^{34}$

In a retrospective cohort of 104 patients receiving alteplase, major bleeding was observed in 20 patients $(19.2 \%)$, with one death. In the multivariate analysis, independent predictors of major bleeding were cancer (OR 16, 95\% CI 3.2 to $80 \mathrm{P}=0.004$ ), diabetes (OR 9.6, $95 \%$ CI 1.7 to $54, \mathrm{P}=0.01)$, an increased international normalized ratio (INR) before fibrinolysis (OR 6, 95\% CI 1.5 to $22, \mathrm{P}=0.012$ ) and catecholamine administration due to systemic hypotension (OR 115, 95\% CI 9.4 to $1.411, \mathrm{P}<0.001) .{ }^{36}$ One recent study focused on identifying the risks for major bleeding in patients who received $100 \mathrm{mg}$ of alteplase as a treatment for PE at a single institution. Significant risk factors in this analysis included major surgery within the previous three weeks (OR $9.00,95 \%$ CI 1.01 to 79.99 ), INR $>1.7$ (OR $13.20,95 \%$ CI 1.54 to 113.52 ), weight $<100 \mathrm{~kg}$ (OR 1.18 for each $10 \mathrm{~kg}$ below $100 \mathrm{~kg}, 95 \%$ CI 1.01 to 1.37 ) and at least one of the following characteristics (OR 5.02, 95\% CI 1.78 to 18.55): 


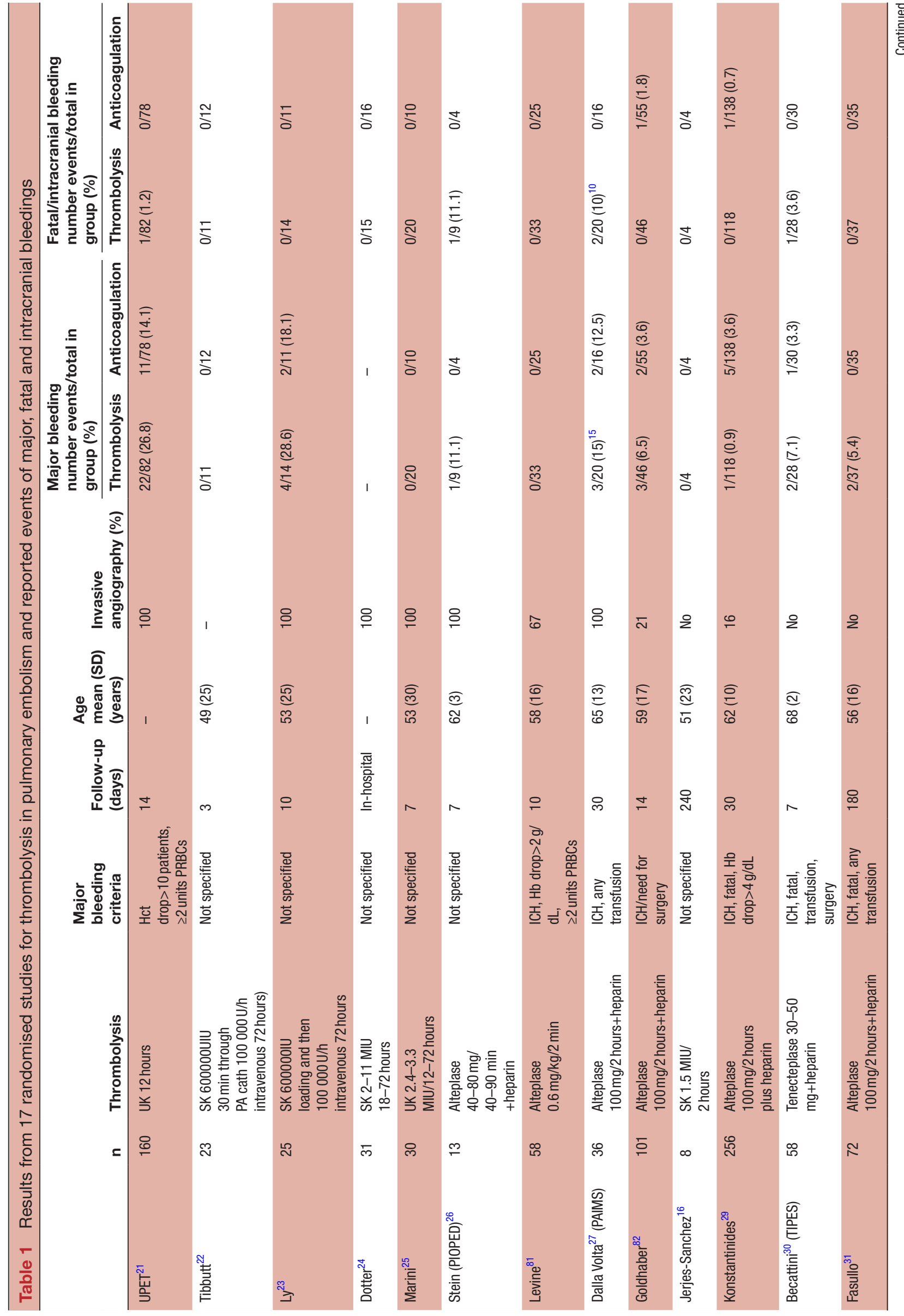




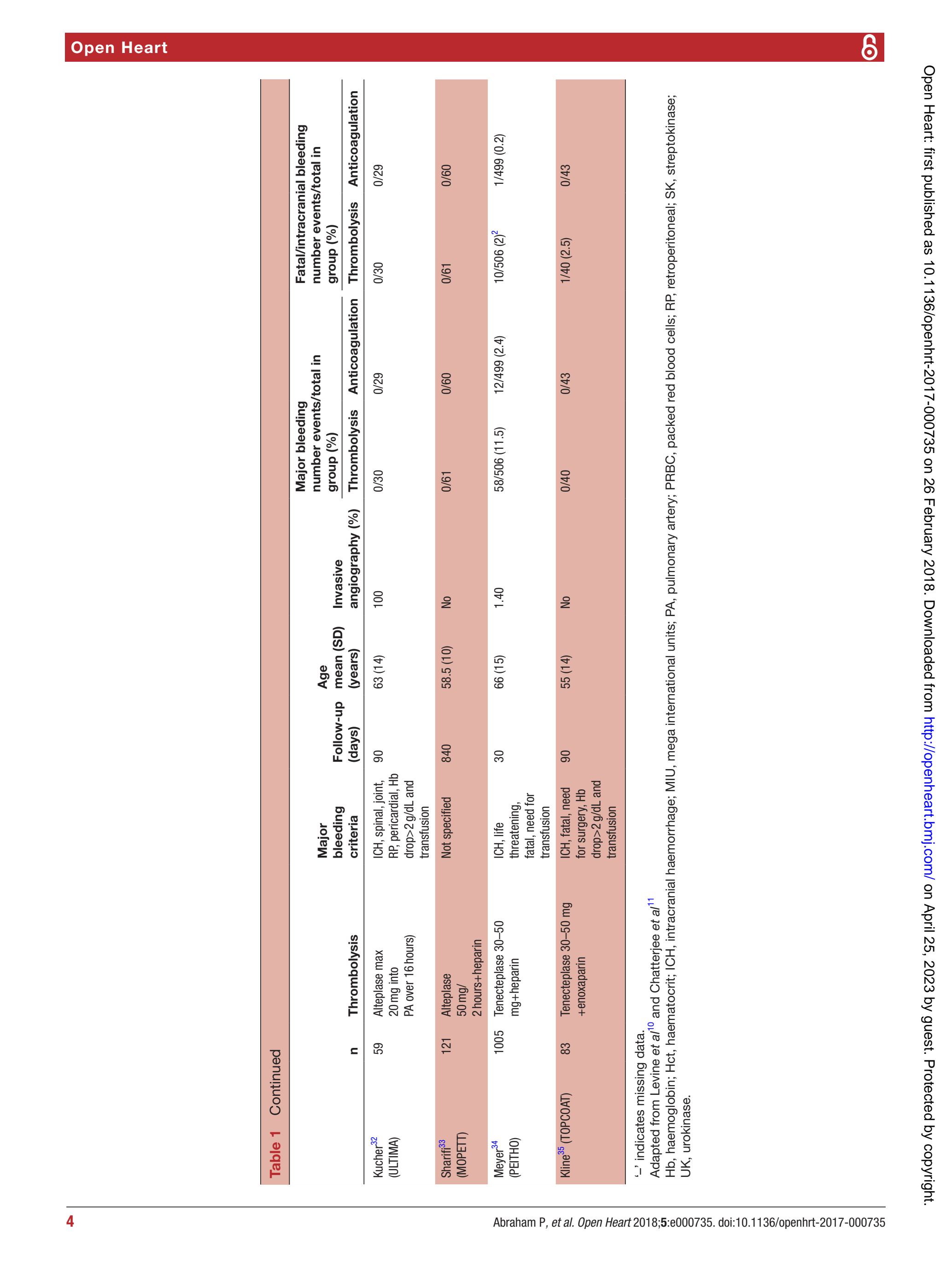




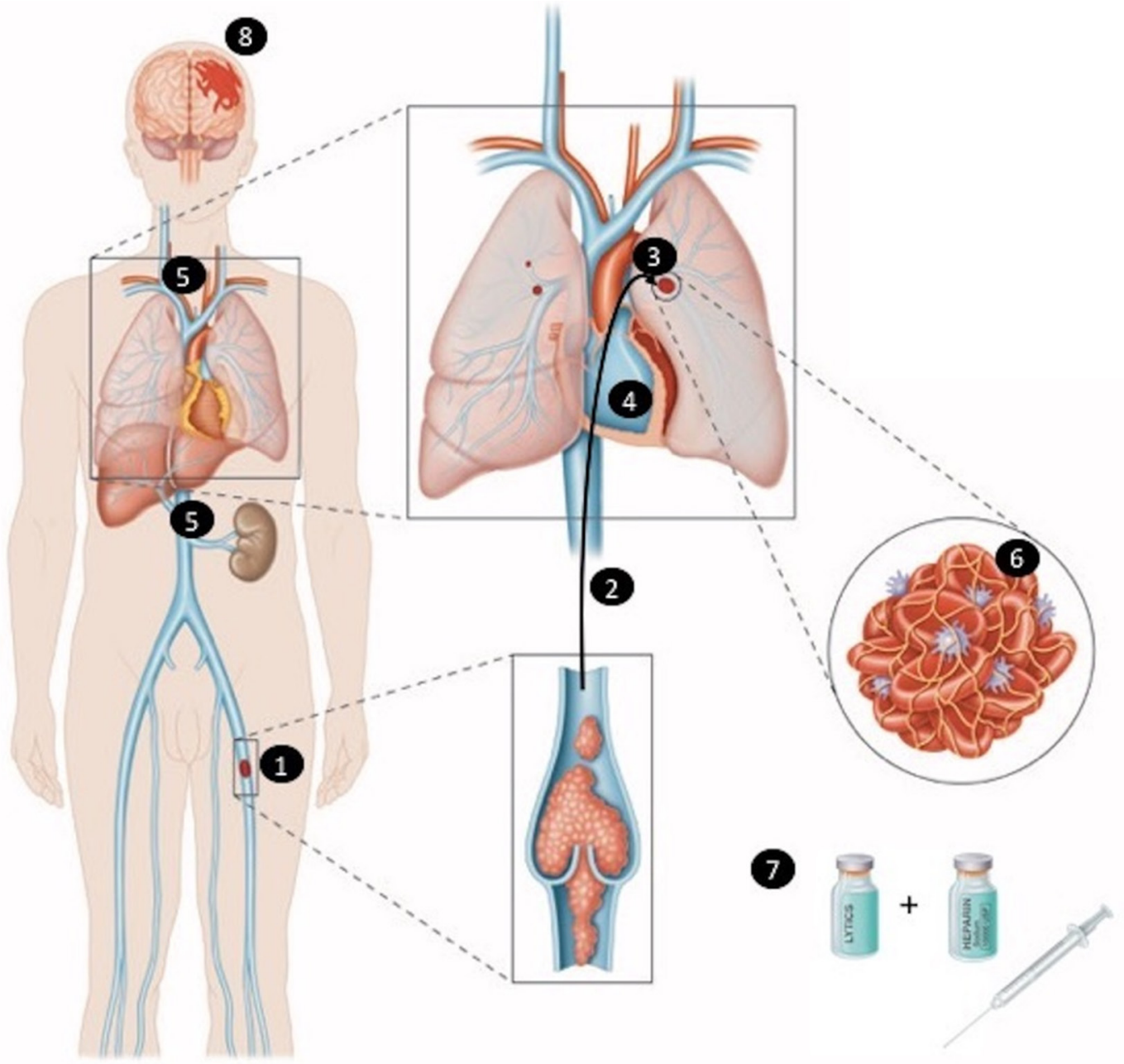

Figure 1 Pathophysiology of high-risk pulmonary embolism (PE) and intracerebral haemorrhage following thrombolysis. In intermediate-risk and high-risk PE, peripheral thrombus (1) and emboli (2) in the arterial pulmonary tree (3) may induce right ventricular dysfunction and sometimes failure (4), leading to a decreased cerebral, renal and hepatic venous return. The venous congestion (5) added to hepatic hypoxaemia, and an impaired renal clearance may affect haemostasis and PE clot sensitivity to lytics (6). Therapies associating heparin infusion and thrombolytics (7) could provoke major bleeding (8).

internal bleeding in the previous fourweeks, hypertension, acute MI, positive occult stool sample, presence of an intra-aortic balloon pump, African-American origin, gastrointestinal bleeding in the preceding three months, aortic dissection, acute pancreatitis, cardiopulmonary resuscitation that exceeded $10 \mathrm{~min}$, bilirubin $>3 \mathrm{mg} / \mathrm{dL}$ or dementia. ${ }^{37}$

In a large population-based study including 9705 patients with PE receiving thrombolysis, of which 176 experienced intracranial bleeding (1.8\%), a logistic regression model identified four independent prognostic factors: peripheral vascular disease, age $>65$ years, $\mathrm{MI}$ and previous stroke with residual deficit. The latter being by far the most significant risk factor (OR 1.99, 95\% CI 1.97 to $2.01, \mathrm{P}=0.007) .{ }^{38}$

Interestingly, in the context of MI, important predictors of bleeding were similar to those found in the PE population and included increased age, lighter weight, female gender, African ancestry and those that had invasive procedures. ${ }^{20}$

\section{EXPLAINING THE HIGHER RISK OF BLEEDING FOR PATIENTS WITH THROMBOLYSIS IN PE COMPARED WITH MI?}

With identical risk factors, why are patients with PE more prone to adverse bleeding events? And if patients with PE are at higher risk of bleeding, is it reasonable to treat two very different diseases in the same way?

We cannot overemphasise the major difference in the pathophysiology of clot formation, and clot burden between PE and MI. The thrombus composition in PE and deep venous thrombosis consists mainly of fibrin and a varying degree of platelets (red clot). ${ }^{39}$ These venous thrombi are often a consequence of either intrinsic factors (surgery, cancer, inherited hypercoagulable states) or mechanisms that predispose the patient to the formation of venous thrombosis as described by Virchow's triad. ${ }^{40}$ The arterial thrombus in MI has a different pathogenesis. It is triggered by an underlying atherosclerotic plaque rupture in the context of turbulent flow that induces a shear stress on arterial wall. This 
stimulates arterial inflammation, which enhances platelet adhesion to the damaged vessel wall, and impairs activation of coagulation factors that cannot aggregate around the formed clot (white clot). ${ }^{42}$ The difference in D-dimer levels (a fibrin degradation product), which are much higher in patients with PE compared with patients with MI, supports this mechanistic difference, but also emphasises the greater activation of the fibrinolytic cascade in patients with PE. ${ }^{43}$

Unsurprisingly, the treatment of these two thrombotic diseases differs: arterial thrombi are treated with drugs that target platelets, while venous thrombi are treated with drugs that target the coagulation cascade. ${ }^{44}$ Venous thrombi may be more sensitive to thrombolytic agents because these drugs act on the fibrin-rich, 'red' component of the thrombus, whereas the platelet-rich, 'white' component (or arterial thrombus) is less affected.

As one hypothesis to explain the higher rate of haemorrhagic complications following thrombolytic therapy in patients with $\mathrm{PE}$, we speculate that venous congestion and an increase in central venous pressure (CVP) could influence the bleeding risk when PE induces acute cor pulmonale (see figure 1) with haemodynamic compromise. There are at least two other clinical scenarios which suggest the relationship between venous congestion and bleeding: cerebral sinus venous thrombosis and cavernous cerebral haemorrhage, ${ }^{45}$ and gastrointestinal bleeding in up to $20 \%$ of patients with chronic portal vein thrombosis. ${ }^{46}$ Moreover, liver injury due to a combination of arterial hypoxaemia, low cardiac output and liver congestion (CVP being the back pressure for hepatic venous return) could be a major factor for the risk of bleeding in patients with acute cor pulmonale and circulatory failure. ${ }^{48}$ Although there are limited data on hypoxic hepatitis in the setting of severe PE, liver dysfunction which induces clotting disorders is a well-known risk factor for haemorrhagic complications. ${ }^{49}$

Another hypothesis may be that some patients with a patent foramen ovale suffer from subclinical shower of small paradoxic emboli which may later lead to frail subclinical ischaemic cerebral foci more prone to bleed under thrombolytic therapy. ${ }^{50}$ Indeed, patent foramen ovale has been shown to triple the stroke rate and more than double mortality in patients with clinically apparent venous thromboembolism. ${ }^{51}$

A final assumption for the seemingly higher rates of bleeding under thrombolysis in PE versus MI may simply be coincidence. Thrombolysis trials in MI have been very large, while the vast majority of PE trials have not exceeded 100 patients. Without a patient-level meta-analysis of all trials, these observations may simply be due to chance.

\section{FUTURE CONSIDERATIONS IN PATIENT MANAGEMENT Improving patient selection for thrombolysis in PE}

The variable clinical results for thrombolysis in PE have been influenced by inappropriate patient selection, for which adverse events and bleeding risks have outweighed the benefits of clot fragmentation. An important challenge in PE management is patient risk stratification. ${ }^{52}$ Cho et al showed that in haemodynamically stable patients with PE 37\% had evidence of right ventricular (RV) dysfunction on ultrasound assessment. ${ }^{53}$ Grifoni et al confirmed in their prospective clinical outcome study that $30 \%$ of normotensive patients had RV dysfunction with $10 \%$ progressing to shock with a hospital mortality of $50 \%$. These patients with latent haemodynamic impairment may require more aggressive therapeutic strategies. ${ }^{54}$

\section{Offering thrombolysis as a rescue therapy in decompensating patients?}

One approach is to treat patients with RV dysfunction but no shock with a heparin infusion, and use thrombolysis as a bailout therapy for the decompensating patient. The risk-benefit analysis would be easier to justify. However, the results of the PEITHO randomised trial did not favour this approach, probably because the key treatment of cor pulmonale is removal of the causa prima. More than 1000 patients with moderate to severe (but all intermediate-risk) PE with RV dysfunction who received thrombolysis showed a statistically significant reduction in morbimortality within the 7 days after randomisation (death or haemodynamic decompensation: OR $0.44,95 \%$ CI 0.23 to $0.87, \mathrm{P}=0.02)$. Moreover, in the heparin-only group, 23 patients died despite 15 of them receiving thrombolysis (with tenecteplase) as rescue therapy. ${ }^{34}$ We may also emphasise that causes of death at 30 days in the placebo group included three haemodynamic collapses, three recurrent PEs, three respiratory failures and two sudden and unexplained deaths, and haemodynamic collapses were three times more frequent in the heparin-only group ( $1.6 \%$ vs $5 \%$, OR $0.30,95 \%$ IC 0.14 to 0.68 ), $\mathrm{P}=0.002$ ). Therefore, the PEITHO randomised trial demonstrated that in patients with RV dysfunction heparin infusion without thrombolysis or with delayed thrombolysis may increase mortality and morbidity. Nevertheless, any potential advantage of thrombolysis was counterbalanced by a five times increased risk of major bleeds and a 10-fold increased risk of (mainly haemorrhagic) stroke.

\section{Considering new fibrinolytic agents or regimens?}

The use of thrombolytic agents is heterogeneous. Streptokinase was, historically, the main agent due to low cost and limited evidence in favour of other agents. ${ }^{55}$ Pharmaceutical engineering then developed 'second generation' fibrin-specific thrombolytic agents. ${ }^{56}$ The 'third generation' thrombolytics is characterised by improved pharmacokinetic properties, including a longer half-life due to a resistance to natural inhibitors; improved fibrin specificity and binding, which increased resistance to plasminogen activator inhibitors (PAI-1) and reduced immunogenicity ${ }^{56}{ }^{57}$ However, despite a massive investment of the pharmaceutical industry, the effects of second-generation and third-generation thrombolytics are somewhat 
disappointing. ${ }^{58}$ Both fundamental and in vitro data from animal studies have not shown significant improvements. Streptokinase is still the most widely used thrombolytic for the treatment of acute MI and by extension, PE. As pointed by Levine 25 years ago, 'The risk of extracranial bleeding is virtually identical, regardless of the thrombolytic agent used within the approved dose ranges. Thus, the concept that relative fibrin specificity per se would protect against serious systemic bleeding has been proved incorrect. ${ }^{59}$ The incidence of the three major conditions requiring thrombolysis, namely STEMI, PE and ischaemic stroke, is unlikely to decrease in the following years. We can only hope for further drug or drug regimen developments with better targeting of fibrin clot and decreased haemorrhagic events. ${ }^{60}$

\section{Reconsidering targets for the management of PE using tailored heparin and thrombolytic infusions?}

The PEITHO study also emphasised the challenge of the concomitant use of heparin infusions. All patients from both the tenecteplase and control groups received a significant heparin bolus, which resulted in an activated partial thromboplastin time of 2.0-2.5 times the upper limit of the normal range. The safety outcome results in the intention-to-treat analysis were an $11.5 \%$ rate of major bleeding, a $6.3 \%$ rate of major extracranial bleeding and a $2 \%$ rate of haemorrhagic stroke. This high incidence of bleeding associated with thrombolysis is in contrast to the International Cooperative of Pulmonary Embolism Registry, which reported a 22\% incidence of major bleeding and a $3 \%$ incidence of intracerebral haemorrhage. ${ }^{14}$ The major bleeding rate associated with heparin infusion alone in the same registry was approximately $15 \% .^{14}$

In another literature review of 559 patients treated for PE with r-tPA (mostly between 50 and $100 \mathrm{mg}$ ), the frequency of intracerebral haemorrhage was $2.1 \% .{ }^{61}$ Interestingly, in a randomised trial from Konstantinides $e t a l$, the alteplase + heparin versus heparin alone bleeding rate were $0.8 \%$ and $3.6 \%(\mathrm{P}=0.29)$, respectively. ${ }^{29}$ Moreover, in the MOPPET trial, there was no major or minor bleeding after the use of a 'low dose' thrombolytic (maximum $50 \mathrm{mg} \mathrm{tPA}$ ) with the aim of an activated partial thromboplastin time of maximum two times the upper limit of normal range. ${ }^{33}$ Anticoagulation with heparin infusion alone increases the risk of bleeding. Recent meta-analyses have included heterogeneous studies, some of which used outdated heparin protocols (both for administration and monitoring). We suggest that lower heparin bolus, strict aPTT (activated partial thromboplastin time), or better, anti-Xa and fibrinogen monitoring may be necessary. Moreover, a targeted approach with tailored thrombolytic dosage is paramount.

Both cardiologists for STEMI and neurologists for ischaemic stroke have addressed the benefit of adjusted or tailored thrombolysis. Studies assessing the efficiency of low-dose thrombolysis for both stroke ${ }^{62} 63$ and STEMI ${ }^{65}$ have shown comparable results to the standard-dose treatment in terms of effectiveness and safety. The same protocol used in the MOPPET trial was performed by the same authors in another cohort of 98 patients with moderate to severe PE with no bleeding due to this 'safe personalised half-dose tPA thrombolysis' ${ }^{66}$ The administration of weight-adjusted, reduceddose rt-PA bolus seemed to produce less coagulation anomalies than current US Food and Drug Administration (FDA)-approved regimens. ${ }^{67}$ Moreover, clinicians now have access to additional point of care testing such as viscoelastometric testing of whole blood or sonic estimation of elasticity via resonance technology, which can complete the initial workup and guide therapy. ${ }^{68}$ One can imagine both titration of the heparin infusion and thrombolytic treatment. These hypotheses however remain to be confirmed in properly designed clinical trials.

\section{Potential long-term benefits of thrombolysis}

Once again, the beneficial impact of thrombolytic therapy is based on scarce data. If immediate mortality seems to be improved in high-risk PE ${ }^{11-13}$ the effect on long-term outcomes is uncertain. In the randomised controlled TOPCOAT study, there were less adverse outcomes and less patients with dyspnoea in the thrombolysis group versus the placebo group. The study was unfortunately terminated prematurely. ${ }^{35}$ In the MOPPET trial, through a mean follow-up of $28 \pm 5$ months, there were fewer patients with pulmonary hypertension after thrombolysis compared with placebo (16\% vs $57 \%$ ). However, the clinical relevance of systematic ultrasound assessment in asymptomatic patients is questionable. Finally, recently published long-term outcome evaluation performed on the PEITHO trial population recommends caution to be taken regarding potential beneficial impact of thrombolytic therapy at distance. ${ }^{69}$ Indeed, no differences were reported between the thrombolysis and placebo arms, regarding mortality rate, functional limitation, residual dyspnoea, residual pulmonary hypertension and RV dysfunction, in this population with intermediate-risk PE. $^{70}$

\section{The need to team up to decide if and when to administer thrombolysis}

Thrombolysis for high-risk PE is mandatory whenever possible. $^{16}$

Despite the abovementioned risk factors, a major shortcoming is the absence of a well-validated scoring system to predict the risk of bleeding in patients with PE. ${ }^{71}$ For patients with no absolute contraindications and deemed at moderate to high bleeding risk, half-dose thrombolysis could be started and then titrated to efficacy. If the administration of lytics is contraindicated, venoarterial extracorporeal membrane oxygenation can offer haemodynamic support in selected patients as a bridge to either recovery or interventional therapy. Urgent surgery is still an option for those patients who are decompensating, even if the published data on morbidity and mortality are 
limited, and probably biased (unfavourable outcomes being under-reported).

Several decades ago, local administration of alteplase in the pulmonary artery did not offer any benefit compared with systemic intravenous administration. ${ }^{72}$ However, catheter-assisted thrombolysis, whereby thrombolysis is administered locally, could be of interest in patients at high bleeding risk. In a review, Kuo et al concluded that it was a safe and effective treatment for acute and highrisk PE. ${ }^{73}$ One example is the EkoSonic Ultrasound-Accelerated Thrombolysis System (EKOS) technique, which uses ultrasonic energy to disrupt the structure of the thrombus, leaving it more susceptible to thrombolytic agents. The catheter combines numerous side-holes that infuse thrombolytics with a filament that includes multiple miniature ultrasound transducers. This recently FDA-approved technique should be delivered only in expert centres. ${ }^{74}$ The ULTIMA study demonstrated that for patients with $\mathrm{PE}$ at intermediate risk of adverse events EKOS treatment was clinically superior to anticoagulation with heparin alone in the improvement of RV function at 24 hours. The SEATTLE II study confirmed these results also showing an improvement in RV function and pulmonary pressure, while decreasing the number of ICHs. ${ }^{327475}$ However, there are no solid data on hard and longer-term outcomes such as chronic pulmonary hypertension and mortality, and it is still unknown whether focused thrombolysis using catheter assistance is more efficient and less risky than systemic thrombolysis. ${ }^{73} 7677$

There is now a broader spectrum of management strategies for patients with intermediate-risk and high-risk PE. We suggest that the management of patients with high-risk PE could undergo a developmental approach analogue to that observed in MI, with systemic thrombolysis being used in patients at low risk of bleeding or not accessible to catheter therapy because of time delay or haemodynamic instability while focused catheter-assisted thrombolysis will be restricted to patients at high risk of bleeding. In our view, thrombolysis should be administered only to high-risk patients with PE at low risk of bleeding. However, catheter-based therapies could be preferred for high risk of bleeding patient presenting with intermediate-high-risk PE. Its place in intermediate-risk patients with PE remains to be established in proper clinical trials. At this stage, however, any treatment that would be at variance with the $1 \mathrm{~B}$ recommendation of the 2016 guidelines of the American College of Chest Physicians that 'in most patients with acute PE not associated with hypotension, we recommend against thrombolytic therapy' should be considered with extreme caution. ${ }^{78}$

In conclusion, PE management is challenging in many ways starting with, at times, deceptive clinical presentations. Thus, a decompensating patient may seem compensated but present with a life-threatening RV dysfunction. The same high-risk patient with PE may be treated completely differently depending on concomitant factors such as age, context and local resources. For these reasons, a multidisciplinary approach should be attempted, for example, a pulmonary embolism response team (PERT), to best manage patients with acute, severe disease. ${ }^{70}$ This shift of approach should to be adjusted according to the usefulness and timing of the intervention; in particular, PE management needs to be tailored to pathophysiology.

Acute cor pulmonale due to PE has a very specific pathophysiology, where patient characteristics and haemodynamic features interact, and may contribute to an increased risk of bleeding following thrombolysis. Future challenges to decrease the bleeding risk and improve clinical outcomes include better bleeding risk stratification, tailored heparin and thrombolysis dosage, improved treatment monitoring, adjunctive catheter-based therapies and implementing multidisciplinary PERTs.

Contributors PA and DAA contributed equally. Both designed, drafted the manuscript and collected the data. KB designed the manuscript and made critical revisions for important intellectual content. HB and RG made critical revisions for important intellectual content. All authors read and approved the final manuscript.

Competing interests $\mathrm{RG}$ received consultant fees from BTG for a presentation at the Pulmonary Embolism Expert Forum (PEEF) in 2017.

Provenance and peer review Not commissioned; externally peer reviewed. Data sharing statement No additional data are available.

Open Access This is an Open Access article distributed in accordance with the Creative Commons Attribution Non Commercial (CC BY-NC 4.0) license, which permits others to distribute, remix, adapt, build upon this work non-commercially, and license their derivative works on different terms, provided the original work is properly cited and the use is non-commercial. See: http://creativecommons.org/ licenses/by-nc/4.0/

(c) Article author(s) (or their employer(s) unless otherwise stated in the text of the article) 2018. All rights reserved. No commercial use is permitted unless otherwise expressly granted.

\section{REFERENCES}

1. Lucena J, Rico A, Vázquez R, et al. Pulmonary embolism and sudden-unexpected death: prospective study on 2477 forensic autopsies performed at the Institute of Legal Medicine in Seville. J Forensic Leg Med 2009;16:196-201.

2. Wiener RS, Schwartz LM, Woloshin S. Time trends in pulmonary embolism in the United States: evidence of overdiagnosis. Arch Intern Med 2011;171:831-7.

3. Tillett WS, Garner RL. The fibrinolytic activity of hemolytic streptococci. J Exp Med 1933;58:485-502.

4. Tillett WS, Sherry S, Read CT. The use of streptokinasestreptodornase in the treatment of postneumonic empyema. J Thorac Surg 1951;21:275-97.

5. Sherry S, Fletcher AP, Alkajersig N, et al. An approach to intravascular fibrinolysis in man. Trans Assoc Am Physicians 1957;70:288-95. discussion 295-6.

6. Effectiveness of intravenous thrombolytic treatment in acute myocardial infarction. Gruppo Italiano per lo Studio della Streptochinasi nell'Infarto Miocardico (GISSI). Lancet Lond Engl 1986;1:397-402.

7. Hirsh J, Hale GS, McDonald IG, et al. Streptokinase therapy in acute major pulmonary embolism: effectiveness and problems. Br Med J 1968;4:729-34.

8. Maroo A, Topol EJ. The early history and development of thrombolysis in acute myocardial infarction. J Thromb Haemost 2004;2:1867-70.

9. Steg PG, James SK, Atar D, et al. ESC Guidelines for the management of acute myocardial infarction in patients presenting with ST-segment elevation. Eur Heart J 2012;33:2569-619.

10. Levine MN, Goldhaber SZ, Califf RM, et al. Hemorrhagic complications of thrombolytic therapy in the treatment of myocardial infarction and venous thromboembolism. Chest 1992;102(4 Suppl):364S-73.

11. Chatterjee S, Chakraborty A, Weinberg I, et al. Thrombolysis for pulmonary embolism and risk of all-cause mortality, major 
bleeding, and intracranial hemorrhage: a meta-analysis. JAMA 2014;311:2414-21.

12. Marti C, John G, Konstantinides S, et al. Systemic thrombolytic therapy for acute pulmonary embolism: a systematic review and meta-analysis. Eur Heart $J$ 2015;36:605-14.

13. Wang TF, Squizzato A, Dentali F, et al. The role of thrombolytic therapy in pulmonary embolism. Blood 2015;125:2191-9.

14. Goldhaber SZ, Visani L, De Rosa M. Acute pulmonary embolism: clinical outcomes in the International Cooperative Pulmonary Embolism Registry (ICOPER). The Lancet 1999;353:1386-9.

15. Meyer G, Gisselbrecht M, Diehl JL, et al. Incidence and predictors of major hemorrhagic complications from thrombolytic therapy in patients with massive pulmonary embolism. $\mathrm{Am} \mathrm{J} \mathrm{Med}$ 1998:105:472-7.

16. Jerjes-Sanchez C, Ramírez-Rivera A, de Lourdes García M, et al. Streptokinase and heparin versus heparin alone in massive pulmonary embolism: a randomized controlled trial. J Thromb Thrombolysis 1995;2:227-9.

17. Assessment of the Safety and Efficacy of a New Treatment Strategy with Percutaneous Coronary Intervention (ASSENT-4 PCI) investigators. Primary versus tenecteplase-facilitated percutaneous coronary intervention in patients with ST-segment elevation acute myocardial infarction (ASSENT-4 PCI): randomised trial. Lancet 2006;367:569-78.

18. Keeley EC, Boura JA, Grines CL. Primary angioplasty versus intravenous thrombolytic therapy for acute myocardial infarction: a quantitative review of 23 randomised trials. Lancet 2003;361:13-20.

19. Simoons $M L$, de Jaegere $P$, van Domburg $R$, et al. Individual risk assessment for intracranial haemorrhage during thrombolytic therapy. The Lancet 1993;342:1523-8.

20. Berkowitz SD, Granger CB, Pieper KS, et al. Incidence and predictors of bleeding after contemporary thrombolytic therapy for myocardial infarction. Circulation 1997;95:2508-16.

21. Urokinase pulmonary embolism trial. Phase 1 results: a cooperative study. JAMA 1970;214:2163-72.

22. Tibbutt DA, Davies JA, Anderson JA, et al. Comparison by controlled clinical trial of streptokinase and heparin in treatment of lifethreatening pulmonay embolism. Br Med J 1974;1:343-7.

23. Ly B, Arnesen $\mathrm{H}$, Eie $\mathrm{H}$, et al. A controlled clinical trial of streptokinase and heparin in the treatment of major pulmonary embolism. Acta Med Scand 1978;203:465-70.

24. Dotter CT, Seaman AJ, Rosch J, et al. Streptokinase and heparin in the treatment of pulmonary embolism. Vasc Surg 1979;13:42-52.

25. Marini C, Di Ricco G, Rossi G, et al. Fibrinolytic effects of urokinase and heparin in acute pulmonary embolism: a randomized clinical trial. Respiration 1988;54:162-73.

26. Tissue plasminogen activator for the treatment of acute pulmonary embolism. A collaborative study by the PIOPED Investigators. Chest 1990;97:528-33

27. Dalla-Volta S, Palla A, Santolicandro A, et al. PAIMS 2: alteplase combined with heparin versus heparin in the treatment of acute pulmonary embolism. Plasminogen activator Italian multicenter study 2. J Am Coll Cardiol 1992;20:520-6.

28. Goldhaber SZ, Agnelli G, Levine MN. Reduced dose bolus alteplase vs conventional alteplase infusion for pulmonary embolism thrombolysis. An international multicenter randomized trial. The Bolus Alteplase Pulmonary Embolism Group. Chest 1994:106:718-24.

29. Konstantinides S, Geibel A, Heusel G, et al. Heparin plus alteplase compared with heparin alone in patients with submassive pulmonary embolism. N Engl J Med 2002;347:1143-50.

30. Becattini C, Agnelli G, Salvi A, et al. Bolus tenecteplase for right ventricle dysfunction in hemodynamically stable patients with pulmonary embolism. Thromb Res 2010;125:e82-6.

31. Fasullo S, Scalzo S, Maringhini G, et al. Six-month echocardiographic study in patients with submassive pulmonary embolism and right ventricle dysfunction: comparison of thrombolysis with heparin. Am J Med Sci 2011;341:33-9.

32. Kucher N, Boekstegers P, Müller OJ, et al. Randomized, controlled trial of ultrasound-assisted catheter-directed thrombolysis for acute intermediate-risk pulmonary embolism. Circulation 2014;129:479-86.

33. Sharifi M, Bay C, Skrocki L, et al. Moderate pulmonary embolism treated with thrombolysis (from the "MOPETT" Trial). Am J Cardiol 2013;111:273-7.

34. Meyer G, Vicaut E, Danays T, et al. Fibrinolysis for patients with intermediate-risk pulmonary embolism. N Engl J Med 2014;370:1402-11.

35. Kline JA, Nordenholz KE, Courtney DM, et al. Treatment of submassive pulmonary embolism with tenecteplase or placebo: cardiopulmonary outcomes at 3 months: multicenter double- blind, placebo-controlled randomized trial. J Thromb Haemost 2014:12:459-68.

36. Fiumara K, Kucher N, Fanikos $\mathrm{J}$, et al. Predictors of major hemorrhage following fibrinolysis for acute pulmonary embolism. Am J Cardiol 2006;97:127-9.

37. Curtis GM, Lam SW, Reddy AJ, et al. Risk factors associated with bleeding after alteplase administration for pulmonary embolism: a case-control study. Pharmacotherapy 2014;34:818-25.

38. Chatterjee S, Weinberg I, Yeh RW, et al. Risk factors for intracranial haemorrhage in patients with pulmonary embolism treated with thrombolytic therapy Development of the PE-CH Score. Thromb Haemost 2017:117:246-51.

39. Rumbaut RE, Arterial TP. Arterial, venous, and microvascular hemostasis/thrombosis: Morgan \& Claypool Life Sciences, 2010. http://www.ncbi.nlm.nih.gov/books/NBK53453/ (cited 2016 Jun 22).

40. Bagot CN, Arya R. Virchow and his triad: a question of attribution. $\mathrm{Br}$ $J$ Haematol 2008;143:180-90.

41. Closse C, Seigneur M, Renard M, et al. Influence of hypoxia and hypoxia-reoxygenation on endothelial P-selectin expression. Thromb Res 1997;85:159-64.

42. Lord ST. Fibrinogen and fibrin: scaffold proteins in hemostasis. Curr Opin Hematol 2007;14:236-41.

43. Kim SJ, Kim MH, Lee KM, et al. Troponin I and D-Dimer for discriminating acute pulmonary thromboembolism from myocardial infarction. Cardiology 2016;136:222-7.

44. Mackman N. Triggers, targets and treatments for thrombosis. Nature 2008:451:914-8.

45. Gross BA, Lin N, Du R, et al. The natural history of intracranial cavernous malformations. Neurosurg Focus 2011;30:E24.

46. Hoekstra J, Janssen HL. Vascular liver disorders (II): portal vein thrombosis. Neth J Med 2009;67:46-53.

47. Ponziani FR, Zocco MA, Campanale C, et al. Portal vein thrombosis: insight into physiopathology, diagnosis, and treatment. World $\mathrm{J}$ Gastroenterol 2010;16:143-55.

48. Henrion J, Descamps O, Luwaert R, et al. Hypoxic hepatitis in patients with cardiac failure: incidence in a coronary care unit and measurement of hepatic blood flow. J Hepatol 1994;21:696-703.

49. Aslan S, Meral M, Akgun M, et al. Liver dysfunction in patients with acute pulmonary embolism. Hepatol Res 2007;37:205-13.

50. Handke M, Harloff A, Olschewski M, et al. Patent foramen ovale and cryptogenic stroke in older patients. N Engl J Med 2007;357:2262-8.

51. Konstantinides S, Geibel A, Kasper W, et al. Patent foramen ovale is an important predictor of adverse outcome in patients with major pulmonary embolism. Circulation 1998;97:1946-51.

52. Konstantinides S, Goldhaber SZ. Pulmonary embolism: risk assessment and management. Eur Heart J 2012;33:3014-22.

53. Cho JH, Kutti Sridharan G, Kim SH, et al. Right ventricular dysfunction as an echocardiographic prognostic factor in hemodynamically stable patients with acute pulmonary embolism: a meta-analysis. BMC Cardiovasc Disord 2014;14:64.

54. Grifoni S, Olivotto I, Cecchini P, et al. Short-term clinical outcome of patients with acute pulmonary embolism, normal blood pressure, and echocardiographic right ventricular dysfunction. Circulation 2000;101:2817-22

55. Bryan J. The rise and fall of the clot buster: a review on the history of Streptokinase. Pharm J. 2014 http://www.pharmaceutical-journal. $\mathrm{com} /$ news-and-analysis/features/the-rise-and-fall-of-the-clot-bustera-review-on-the-history-of-streptokinase/20065679.article (cited 23 May 2016).

56. Sinnaeve P, Van de Werf F. Thrombolytic therapy. State of the art Thromb Res 2001;103(Suppl 1):S71-9.

57. Verstraete M. Third-generation thrombolytic drugs. Am J Med 2000;109:52-8

58. Longstaff $\mathrm{C}$, Thelwell C. Understanding the enzymology of fibrinolysis and improving thrombolytic therapy. FEBS Lett 2005;579:3303-9.

59. Levine MN, Goldhaber SZ, Gore JM, et al. Hemorrhagic complications of thrombolytic therapy in the treatment of myocardial infarction and venous thromboembolism. Chest 1995;108(4 Suppl):291S-301.

60. Singh S, Houng A, Reed GL. Releasing the brakes on the fibrinolytic system in pulmonary emboli: unique effects of plasminogen activation and $\alpha 2$-Antiplasmin inactivation. Circulation 2017; 135:1011-20.

61. Dalen JE, Alpert JS, Hirsh J. Thrombolytic therapy for pulmonary embolism: is it effective? Is it safe? When is it indicated? Arch Intern Med 1997:157:2550.

62. Kim BJ, Han MK, Park TH, et al. Low-versus standard-dose alteplase for ischemic strokes within 4.5 hours: a comparative effectiveness and safety study. Stroke 2015;46:2541-8. 
63. Kono S, Deguchi K, Morimoto N, et al. Intravenous thrombolysis with neuroprotective therapy by edaravone for ischemic stroke patients older than 80 years of age. J Stroke Cerebrovasc Dis 2013;22:1175-83.

64. Grines CL, Nissen SE, Booth DC, et al. A new thrombolytic regimen for acute myocardial infarction using combination half dose tissuetype plasminogen activator with full dose streptokinase: a pilot study. KAMIT Study Group. J Am Coll Cardiol 1989;14:573-80.

65. Grines CL, Nissen SE, Booth DC, et al. A prospective, randomized trial comparing combination half-dose tissue-type plasminogen activator and streptokinase with full-dose tissue-type plasminogen activator. Kentucky Acute Myocardial Infarction Trial (KAMIT) Group. Circulation 1991;84:540-9.

66. Sharifi M, Bay C, Schwartz F, et al. Safe-dose thrombolysis plus rivaroxaban for moderate and severe pulmonary embolism: drip, drug, and discharge. Clin Cardiol 2014;37:78-82.

67. Agnelli G, lorio A, Parise P, et al. Fibrinogenolysis and thrombin generation after reduced dose bolus or conventional rt-PA for pulmonary embolism. The Coagulation Project Investigators of the Bolus Alteplase Pulmonary Embolism Group. Blood Coagul Fibrinolysis 1997;8:216-22.

68. Ferrante EA, Blasier KR, Givens TB, et al. A novel device for the evaluation of hemostatic function in critical care settings. Anesth Analg 2016;123:1372-9.

69. Goldhaber SZ. PEITHO long-term outcomes study: data disrupt dogma. J Am Coll Cardiol 2017;69:1545-8.

70. Konstantinides SV, Vicaut E, Danays T, et al. Impact of thrombolytic therapy on the long-term outcome of intermediate-risk pulmonary embolism. J Am Coll Cardiol 2017;69:1536-44.

71. Daley MJ, Murthy MS, Peterson EJ. Bleeding risk with systemic thrombolytic therapy for pulmonary embolism: scope of the problem. Ther Adv Drug Saf 2015;6:57-66.

72. Verstraete M, Miller GA, Bounameaux H, et al. Intravenous and intrapulmonary recombinant tissue-type plasminogen activator in the treatment of acute massive pulmonary embolism. Circulation 1988;77:353-60
73. Kuo WT, Gould MK, Louie JD, et al. Catheter-directed therapy for the treatment of massive pulmonary embolism: systematic review and meta-analysis of modern techniques. J Vasc Interv Radiol 2009;20:1431-40.

74. Owens CA. Ultrasound-enhanced thrombolysis: EKOS endowave infusion catheter system. Semin Intervent Radiol 2008;25:037-41.

75. Bloomer TL, El-Hayek GE, McDaniel MC, et al. Safety of catheterdirected thrombolysis for massive and submassive pulmonary embolism: Results of a multicenter registry and meta-analysis. Catheter Cardiovasc Interv 2017;89:754-60.

76. Macovei L, Presura RM, Arsenescu Georgescu C. Systemic or local thrombolysis in high-risk pulmonary embolism. Cardiol $\mathrm{J}$ 2015;22:467-74.

77. Tajima H, Murata S, Kumazaki T, et al. Hybrid treatment of acute massive pulmonary thromboembolism: mechanical fragmentation with a modified rotating pigtail catheter, local fibrinolytic therapy, and clot aspiration followed by systemic fibrinolytic therapy. AJR Am J Roentgenol 2004;183:589-95.

78. Kearon C, Akl EA, Ornelas J, et al. Antithrombotic therapy for VTE disease: CHEST guideline and expert panel report. Chest 2016;149:315-52.

79. Dudzinski DM, Piazza G. Multidisciplinary pulmonary embolism response teams. Circulation 2016;133:98-103.

80. Kabrhel C, Jaff MR, Channick RN, et al. A multidisciplinary pulmonary embolism response team. Chest 2013;144:1738-9.

81. Levine $\mathrm{M}$, Hirsh $\mathrm{J}$, Weitz $\mathrm{J}$, et al. A randomized trial of a single bolus dosage regimen of recombinant tissue plasminogen activator in patients with acute pulmonary embolism. Chest 1990;98:1473-9.

82. Goldhaber SZ, Haire WD, Feldstein ML, et al. Alteplase versus heparin in acute pulmonary embolism: randomised trial assessing right-ventricular function and pulmonary perfusion. Lancet 1993;341:507-11. 